\title{
Updated cost-of-care estimates for commercially insured patients with multiple sclerosis: retrospective observational analysis of medical and pharmacy claims data
}

\author{
Cathryn A Carroll ${ }^{1}$, Kathleen A Fairman ${ }^{2^{*}}$ and Maureen J Lage ${ }^{3}$
}

\begin{abstract}
Background: For patients with multiple sclerosis (MS), previous research identified key disease sequelae as important cost drivers and suggested that among users of disease-modifying drugs (DMDs) in 2004, DMDs represented 73\% of the total cost of care. More recent studies were limited to incident disease/treatment and/or excluded DMDs from cost estimates. To support contemporary pharmacoeconomic analyses, the present study was conducted to provide updated information about MS-related costs and cost drivers including DMDs.

Methods: For each of 2 years, 2006 and 2011, commercially insured, continuously eligible patients with $\geq 1$ medical claim diagnosis of MS were sampled. MS-related charges were based on medical claims with MS diagnosis plus medical/pharmacy claims for DMDs. 2006 charges were adjusted to 2011 \$ using the medical care component of the consumer price index (CPI). Subgroups of patients using DMDs (interferon [IFN] beta-1a intramuscular or subcutaneous, IFN beta-1b, glatiramer, natalizumab) in 2011 were identified. By-group differences were tested with bivariate statistics.

Results: Mean (standard deviation [SD]) age of 15,902 sample patients in 2011 was 47.6 (11.8) years, 76\% female. Mean [SD] MS charges $(\$ 26,520[\$ 38,478]$ overall) were significantly $(P<0.001)$ higher for patients with common disease sequelae: malaise/fatigue $(n=2,235 ; \$ 39,948[\$ 48,435])$, paresthesia $(n=1,566 ; \$ 33,648[\$ 45,273])$, depression $(n=1,255$; $\$ 42,831$ [\$51,693]), and abnormality of gait $(n=1,196 ; \$ 48,361$ [\$55,472]). From 2006 to 2011, CPI-adjusted MS charges increased by $60 \%$. Among patients treated with a single DMD in 2011, inpatient care was 6\% of charges (range $=4 \%-8 \%$; $P=0.155$ ); outpatient care was 19\% (range $=14 \%-20 \%$ except for natalizumab [29\%]; $P<0.001$ ); and DMDs were 75\% (range $=67 \%-81 \%$; $P<0.001$ ).
\end{abstract}

Conclusions: Common MS sequelae remain important cost drivers. Although MS treatment costs are increasing, the proportion of MS charges due to DMDs in 2011 is similar to that reported in 2004.

\section{Background}

Multiple sclerosis (MS) is a chronic, disabling disorder of the central nervous system that typically presents initially in early adulthood, with symptoms and disease progression rates that vary widely among patients [1]. Although MS is rare, affecting less than $0.1 \%$ of the U.S. population [2], its effects on patient functioning and on medical service utilization result in high direct and indirect costs, estimated in 1998 to total $\$ 2.2$ million per U.S.

\footnotetext{
* Correspondence: kathleen@kathleenfairman.com

${ }^{2}$ Kathleen Fairman LTD, 11208 North 23rd Place, Phoenix, AZ, USA

Full list of author information is available at the end of the article
}

case per lifetime [3]. Natural history studies conducted prior to the introduction of disease-modifying drugs (DMDs) to the market (initially interferon [IFN] beta-1b in 1993; IFN beta-1a intramuscular [IM] and glatiramer acetate in 1996) [4] found considerable functional deterioration in the years following disease onset [5]. For example, at 10 years post-onset, one-half of patients were unable to perform daily employment or household activities; and at 15 years, one-half were unable to walk without assistance [5].

DMD treatment of MS early in the disease course, especially for patients with relapsing-remitting MS (RRMS) and to a lesser extent for patients at risk of developing

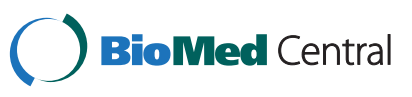


clinically definite MS (CDMS), is becoming a standard of care in the United States [4,6]. In 2002, a joint task force of the American Academy of Neurology and MS Council for Clinical Practice Guidelines recommended that IFN beta treatment be considered "in any patient who is at high risk for developing [CDMS], or who already has either RRMS or secondary progressive MS (SPMS) and is still experiencing relapses" and that treatment with glatiramer be considered for patients with RRMS [6]. A 2008 disease management consensus statement from the National Multiple Sclerosis Society indicated that treatment with an IFN beta medication or glatiramer "should be considered as soon as possible following a definite diagnosis of MS with active, relapsing disease, and may also be considered for selected patients with a first attack who are at high risk of MS" [7].

Growing consensus about the use of DMDs in MS treatment has heightened the importance of MS cost-ofcare analyses for health care payers, including employers. DMDs are high-cost medications, with one economic analysis estimating total treatment expense including laboratory monitoring costs at $\$ 2,294$ to $\$ 2,461$ per month (2008 U.S.\$) [8]. However, because both direct medical care costs and societal costs (e.g., payments for disability and sick leave, value of caregiver time) increase as the disease advances [9], the efficacy of DMDs in slowing the progression of MS has the potential to offset drug acquisition costs with savings on other resources.

For example, Prescott et al. found that among patients using a single DMD (monotherapy) in 2004, $75 \%$ of total MS treatment cost was attributable to prescription drugs, with $73 \%$ solely for the DMD [10]. However, they compared their results with those of a previous cost-ofcare estimate by Pope et al. and concluded that after accounting for inflation, "the cost structure for treating MS has changed notably"-from a total 1-year cost of $\$ 9,515$ with $18 \%$ for prescription drugs in 1995 , to $\$ 12,879$ with $65 \%$ for prescription drugs in $2004[10,11]$. Estimating that inflation-adjusted annual medical cost per patient with MS had declined from \$7,802 in 1995 to $\$ 4,529$ in 2004 , Prescott et al. suggested that the downward shift "may be related to the effectiveness of DMD therapy in managing MS severity and reducing functional disability" [10].

In addressing questions about effective treatment approaches and cost of care, payers commonly turn to published observational studies or to pharmacoeconomic models, which rely on input data to produce information about expected "real-world" costs and outcomes [12,13]. However, published data about MS treatment costs are not timely or complete. Early cost estimates by WhettenGoldstein et al. and Pope et al. were based on data collected in 1994-1997 [3,11]. The study by Prescott et al. provided a comprehensive descriptive analysis of the components of MS treatment costs for a large sample but was based on dates of service in 2004 [10]. Analyses published since then have been subject to several common limitations. Many studied only patients with incident disease and/or treatment, who might not accurately represent payers' cost experiences with prevalent disease populations [14-19]. All studied patients initiating treatment prior to 2009 [14-20]. Several excluded DMD costs in reporting the cost of care $[16,18,20]$. These inadequacies in the evidence base are consequential because of important changes in MS treatment in recent years: the publication of several new treatment guidelines [21,22]; the withdrawal of natalizumab from the market in February 2005 followed by its reintroduction in June 2006 under a risk mitigation strategy [23,24]; the approval of a new, branded IFN beta-1b in August 2009 [25]; and the availability of an oral DMD, fingolimod, beginning in September 2010 [4].

To address these gaps in the research literature, the primary objective of the present study was to support pharmacoeconomic analyses of MS treatments by providing an updated assessment of direct health care costs in a contemporary, prevalent cohort of patients with MS, replicating the work of Prescott et al. as closely as possible [10]. The secondary objective, again replicating the method used by Prescott et al., was to assess the growth in medical and drug costs over time by comparing aggregated cost data for prevalent samples in 2006 and 2011.

\section{Methods}

\section{Design and data source}

The study was a retrospective analysis of the i3 Invision ${ }^{\text {in }}$ Data Mart, an integrated database of medical claims, pharmacy claims, and eligibility data for approximately 14 million enrollees of a national health insurance organization. All enrollees were commercially insured, and most were located in the southern or midwestern United States. Available fields on medical claims included International Classification of Diseases, Ninth Revision, Clinical Modification (ICD-9-CM) codes for up to 5 diagnoses, as well as procedure codes (Current Procedural Terminology [CPT], revenue, and Healthcare Common Procedure Coding System [HCPCS]). Pharmacy claims fields included drug brand names, national drug code (NDC) numbers, fill dates, and days supply. Data were collected as part of normal business operations and de-identified prior to delivery to the investigators in accordance with Health Insurance Portability and Accountability Act (HIPAA) requirements. Although the study by Prescott et al. used proprietary Episode Treatment Group (ETG) software to calculate some study outcomes [10], the present study used only data elements that are widely available in administrative claims databases. 


\section{Sample selection}

The same sampling process was used to produce MS patient cohorts for each of the 2 study years, 2006 and 2011. All study patients had (1) at least 1 medical claim with a diagnosis of MS, defined as either an ICD-9-CM = 340.xx in any diagnosis field or a diagnosis-related group (DRG) code for MS and cerebellar ataxia (DRG = 058, 059, or 060) at any time during the study year and (2) continuous eligibility for medical and pharmacy benefits throughout the study year.

For 2011, a subgroup of patients with at least 1 claim for a DMD was created. From this subgroup, an additional subgroup of patients treated with claims for only a single DMD (monotherapy) was identified. DMDs included IFN beta-1a subcutaneous (SC), IFN beta-1a IM, IFN beta-1b, glatiramer acetate, and natalizumab and were identified either by brand name on pharmacy claims or HCPCS codes on medical claims (Table 1).

\section{Analysis}

Consistent with the analyses performed by Prescott et al., study outcomes reported for 2011 included mean (standard deviation [SD]) charges for MS services by geographic region, insurance type, age group, sex, and presence of selected disease sequelae, which were described as comorbidities in the report by Prescott et al. MS services were defined based on a diagnosis of MS (ICD-9-CM or DRG as described above) in any field on medical claims or receipt of a DMD as indicated in either medical or pharmacy claims. Costs were defined as submitted charges minus any expense that was not covered because of incomplete information or ineligible services, patients, or providers. For this reason, we use the term "charge" rather than "cost" throughout the rest of this report.

To identify disease sequelae, diagnoses in any field were used. Each condition (abnormality of gait; ataxia; paresthesia [burning, numbness, or tingling]; convulsions; depression; fecal incontinence; fibromyalgia/myalgia; malaise and fatigue; optic neuritis; spasms; trigeminal neuralgia; urinary incontinence; and voice disturbance) was identified

Table 1 Disease-modifying drugs for multiple sclerosis

\begin{tabular}{lll}
\hline Brand Name & Generic Name & HCPCS Codes $^{\mathrm{a}}$ \\
\hline Avonex $^{\mathrm{b}}$ & IFN beta-1a IM & J1825, Q3025 \\
Betaseron $^{\mathrm{b}}$, Extavia & IFN beta-1b SC & J1830 \\
Copaxone $^{\mathrm{b}}$ & Glatiramer acetate & $\mathrm{J} 1595$ \\
Gilenya $^{\mathrm{b}}$ & Fingolimod & None \\
Rebif $^{\mathrm{b}}$ & IFN beta-1a SC & J1826, Q3026 \\
Tysabri $^{\mathrm{b}}$ & Natalizumab & J2323, Q4079 \\
\hline
\end{tabular}

${ }^{a}$ Drugs were identified by brand names on pharmacy claims and HCPCS codes on medical claims.

${ }^{b}$ Indicates a DMD included in the study by Prescott et al. [10]. $\mathrm{DMD}=$ disease-modifying drug; $\mathrm{HCPCS}=$ Healthcare Common Procedure Coding System; IFN = interferon; IM = intramuscular; $\mathrm{SC}=$ subcutaneous. using coding similar to that of Prescott et al., except that: (1) Prescott et al. used a combination of ICD-9-CM codes and ETGs to identify disease sequelae, and (2) in the present study, a DRG of 881 (depressive neuroses) was used in addition to ICD-9-CM coding to identify depression.

Additional analyses for 2011 included assessments of MS-related utilization and charges by service category (inpatient, outpatient emergency room, and DMD) and separate analyses of DMD monotherapy users by drug. Although patients treated with fingolimod were included in the sample overall, they were excluded from the DMDspecific analyses because of small subgroup size $(n=306)$. A final analysis compared the distribution of MS-related total, medical, and DMD charges for the 2 years, 2006 and 2011, with 2006 charges adjusted to 2011 values using the medical care component of the Consumer Price Index.

Although the analytic approach was descriptive, inferential statistical tests, including Pearson chi-square for categorical variables and $\mathrm{t}$-tests and Analysis of Variance (ANOVA) for interval- or ratio-scale variables, were used [10]. No multivariate adjustments were made because the primary purpose of the study was to provide descriptive cost data for input into pharmacoeconomic models, not to assess the cost-effectiveness of the various available DMDs. Statistical analyses were performed using SAS version 9.2 and an a priori significance level of 0.05 .

\section{Results}

Of potential study subjects with an MS diagnosis or DRG code during each of the 2 study years $(n=21,112$ in 2006 and 20,653 in 2011), more than $70 \%(n=15,399$ in 2006 and 15,902 in 2011) were continuously eligible and constituted the MS patient cohort (Figure 1). Of continuously enrolled patients, the proportions with at least 1 DMD claim were 54\% $(\mathrm{n}=8,248)$ in 2006 and 53\% $(\mathrm{n}=8,451)$ in 2011.

The mean (SD) age for the 2011 cohort was 47.6 (11.8) years, and $76 \%$ of study subjects were female (Table 2). The mean (SD) total MS health care charge in 2011 for the sample overall was $\$ 26,520(\$ 38,478)$. MS charges were slightly but significantly higher for males compared with females. Charges were distributed in an inverted " $U$ " shape by age, with the lowest charges for patients younger than 18 years $(<1 \%$ of the sample; mean of $\$ 14,142)$, increasing incrementally to means of $\$ 27,430-\$ 27,558$ for those aged 36 to 55 years (57\% of the sample), and dropping to a mean of $\$ 21,167$ among those aged 65 years or older ( $5 \%$ of the sample).

Charges did not significantly differ by geographic region but did differ by insurance product type (Table 2). Among common insurance product types (i.e., not in the "other" category), mean MS charges ranged from a low of $\$ 22,127$ in indemnity plans to a high of $\$ 27,933$ in exclusive provider organizations. 
For the sample overall (including both DMD-treated patients and those without DMD use), inpatient services made up $12 \%$ and DMDs 53\% of total MS-related charges in 2011 (Table 2). Measured by claims volume, the most commonly used services were outpatient, constituting $62 \%$ of claims and 35\% of total MS-related charges.

Subgroup analyses of patients with selected disease sequelae indicated that both high- and low-prevalence conditions were associated with substantially increased MS charges (Table 3$)$. Patients with optic neuritis $(n=38)$ had the highest mean charges $(\$ 82,134 ; P=0.001)$, followed by those with abnormality of gait $(n=1,196)$, spasms $(n=412)$, and ataxia $(n=347)$, with means of $\$ 48,337$ to $\$ 48,605$ (all $P<0.001)$. Urinary incontinence $(\mathrm{n}=339)$ and depression $(n=1,255)$ were also associated with high MS charges at means of $\$ 47,885$ and $\$ 42,831$, respectively (both $P<0.001)$. The highest-prevalence sequela was malaise and fatigue, diagnosed in $14.1 \%$ of patients $(n=2,235)$ and associated with a mean MS charge of $\$ 39,948$.

For the subgroup of 8,145 patients with at least 1 injectable DMD claim in 2011, the most frequently used product was glatiramer acetate $(40 \%)$, followed by IFN beta-1a IM (22\%), IFN beta-1a SC (21\%), IFN beta-1b (11\%), and natalizumab (10\%; Table 4). Similar DMD use rates were identified in the subgroup of monotherapytreated patients. However, both the mean claims count and the mean days supply were lower for glatiramer acetate compared with the other DMDs. A post hoc follow-up analysis of this finding indicated that the mean number of days until DMD start, defined as the count of calendar days from January 1, 2011, through the first DMD claim date, was greater $(P<0.001)$ for patients treated with glatiramer acetate (76.4 days) compared with other DMDs (41.6 to 54.2 days).
Among monotherapy users, the most notable bygroup differences were higher rates of nearly all disease sequelae for natalizumab-treated patients (Table 4). For example, the rate of malaise/fatigue was $28 \%$ in the natalizumab monotherapy group compared with 12\%-17\% for the other DMDs, and abnormality of gait was experienced by $16 \%$ in the natalizumab group compared with $6 \%-10 \%$ in the other groups. Natalizumab-treated patients also experienced higher rates of ataxia, paresthesia, depression, fibromyalgia/myositis, spasms, and urinary incontinence. Patients treated with natalizumab monotherapy had the highest mean total MS charges $(\$ 81,627)$, followed by patients treated with IFN beta-1b $(\$ 48,529)$, IFN beta1a IM and SC (\$45,770-\$45,928), and glatiramer acetate $(\$ 38,509 ;$ Table 4). Service categories with significant bygroup differences included outpatient (mean $\$ 23,702$ for natalizumab versus $\$ 6,485-\$ 7,931$ for the remaining DMDs) and DMD ( $\$ 54,255$ for natalizumab versus $\$ 27,694-\$ 37,498$ for the remaining DMDs). DMDs accounted for $75 \%$ of total MS-related charges overall, ranging from a low of $67 \%$ for natalizumab to a high of $81 \%$ for IFN beta-1a IM.

In the sample overall from 2006 to 2011, total mean MS charges per patient after adjustment for medical cost inflation increased by $60 \%$, from $\$ 16,614$ to $\$ 26,520$ (Table 5). Medical charges rose at a lower rate (33\%) than did DMD charges (96\%). Expressed as a proportion of the total, medical charges declined from 57\% in 2006 to $47 \%$ in 2011 .

\section{Discussion}

The present study sought to replicate and update a previously published, comprehensive assessment of MSrelated health care costs using a retrospective analysis of a large database of commercially insured patients. The 
Table 2 MS charges ${ }^{\mathrm{a}}$ in 2011

\begin{tabular}{|c|c|c|c|c|}
\hline & $\mathrm{N}$ & $\%$ of Total & Mean [SD] charge per patient (\$) & $P$ Value \\
\hline All patients & 15,902 & 100.0 & $26,520[38,478]$ & \\
\hline \multicolumn{5}{|l|}{ By patient characteristics } \\
\hline Gender & & & & $<0.001^{\mathrm{b}}$ \\
\hline Female & 12,100 & 76.1 & $26,224[38,716]$ & \\
\hline Male & 3,801 & 23.9 & $27,445[37,691]$ & \\
\hline Unknown & 1 & 0.0 & $90,704[N A]$ & \\
\hline Age in years & & & & $<0.001$ \\
\hline 17 or younger & 126 & 0.8 & $14,142[40,310]$ & \\
\hline 18 to 25 & 405 & 2.6 & $25,731[44,296]$ & \\
\hline 26 to 35 & 2,009 & 12.6 & $26,324[36,224]$ & \\
\hline 36 to 45 & 4,021 & 25.3 & $27,430[36,866]$ & \\
\hline 46 to 55 & 5,030 & 31.6 & $27,558[39,653]$ & \\
\hline 56 to 64 & 3,499 & 22.0 & $25,876[38,022]$ & \\
\hline 65 or older & 812 & 5.1 & $21,167[42,005]$ & \\
\hline \multicolumn{5}{|l|}{ Region } \\
\hline Northeast & 1,861 & 11.7 & $27,035[38,558]$ & 0.646 \\
\hline Midwest & 4,480 & 28.2 & $25,820[32,754]$ & \\
\hline South & 6,730 & 42.3 & $26,604[40,196]$ & \\
\hline West & 2,827 & 17.8 & $27,093[42,457]$ & \\
\hline Other & 4 & 0.0 & $23,745[28,601]$ & \\
\hline Insurance product & & & & 0.032 \\
\hline EPO & 2,088 & 13.1 & $27,933[42,360]$ & \\
\hline $\mathrm{HMO}$ & 1,474 & 9.3 & $24,628[33,046]$ & \\
\hline Indemnity & 329 & 2.1 & $22,127[39,181]$ & \\
\hline POS & 11,336 & 71.3 & $26,648[38,173]$ & \\
\hline PPO & 641 & 4.0 & $26,622[41,918]$ & \\
\hline Other & 34 & 0.2 & $19,353[28,310]$ & \\
\hline Charge components & \multicolumn{2}{|c|}{$\begin{array}{l}\text { Utilization }^{c} \\
\text { Mean [SD] }\end{array}$} & Mean [SD] Cost (\$) & $\%$ of Total Cost \\
\hline Inpatient $^{d}$ & \multicolumn{2}{|c|}{$0.48[2.75]$} & $3,179[17,860]$ & 12.0 \\
\hline Outpatient $^{d}$ & \multicolumn{2}{|c|}{$6.05[8.04]$} & $9,355[24,523]$ & 35.3 \\
\hline Emergency Room ${ }^{d}$ & \multicolumn{2}{|c|}{$0.03[0.39]$} & 33 [522] & 0.1 \\
\hline DMD & \multicolumn{2}{|c|}{$3.17[4.87]$} & $13,953[21,704]$ & 52.6 \\
\hline
\end{tabular}

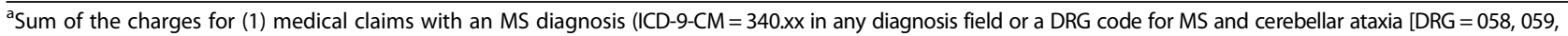
or 060]) plus (2) medical or pharmacy claims indicating a DMD (Table 1).

${ }^{b}$ Excluding the patient with unknown gender (i.e., $t$-test for female versus male).

cNumber of claims. Claims counts for DMDs include both medical and pharmacy claims.

${ }^{d}$ Charges for medical claims with an MS diagnosis (ICD-9-CM $=340 . x x$ in any diagnosis field or a DRG code for MS and cerebellar ataxia [DRG $=058,059$, or 060]). $\mathrm{DMD}=$ disease-modifying drug; DRG = Diagnosis-Related Group; EPO = exclusive provider organization; $\mathrm{HMO}=$ health maintenance organization; $\mathrm{MS}=$ multiple sclerosis; $\mathrm{NA}=$ not applicable; $\mathrm{POS}=$ point of service; $\mathrm{PPO}=$ preferred provider organization; $\mathrm{SD}=$ standard deviation.

study's primary aim was to provide current data, described in a 2013 comprehensive economic review of MS treatment cost-effectiveness as "sorely needed" because of "advances during the last decade in the care and treatment of MS" [26]. Because pharmacoeconomic models constitute the vast bulk of the literature on MS treatment costeffectiveness (32 of the 37 studies included in the 2013 review), results of descriptive cost analyses can be, and often are, used as model input values that should be regularly updated as new information becomes available [27].

The study sample was drawn from a large, frequently used, national database of insurance claims and was demographically similar to that of Prescott et al., with a mean age of 47.6 years and percentage female of $76 \%$, compared 
Table 3 MS charges ${ }^{a}$ by presence of selected disease sequelae in 2011

\begin{tabular}{|c|c|c|c|c|c|}
\hline Condition & Diagnosis code $^{b}$ & $\mathbf{N}$ & Prevalence & Mean $[S D]$ charges $(\$)$ & $P$ Value \\
\hline Abnormality of gait & 781.2 & 1,196 & 7.5 & $48,361[55,472]$ & $<0.001$ \\
\hline Ataxia & 781.3 & 347 & 2.2 & $48,605[63,100]$ & $<0.001$ \\
\hline Burning, numbness, tingling sensations & 782.0 & 1,566 & 9.8 & $33,648[45,273]$ & $<0.001$ \\
\hline Convulsions $^{c}$ & 780.3 & 0 & 0.0 & - & - \\
\hline Depression $^{d}$ & $296.2,296.3,300.4,311 ; \mathrm{DRG}=881$ & 1,255 & 7.9 & $42,831[51,693]$ & $<0.001$ \\
\hline Fecal incontinence & 787.6 & 0 & 0.0 & - & - \\
\hline Fibromyalgia/myalgia and myositis & 729.1 & 399 & 2.5 & $38,319[63,441]$ & $<0.001$ \\
\hline Malaise and fatigue ${ }^{c}$ & 780.7 & 2,235 & 14.1 & $39,948[48,435]$ & $<0.001$ \\
\hline Optic neuritis & 341.0 & 38 & 0.2 & $82,134[98,886]$ & 0.001 \\
\hline Spasms & 781.0 & 412 & 2.6 & $48,337[52,475]$ & $<0.001$ \\
\hline Trigeminal neuralgia & 350.1 & 150 & 0.9 & $38,165[46,506]$ & 0.002 \\
\hline Urinary incontinence ${ }^{c}$ & 788.3 & 339 & 2.1 & $47,885[49,226]$ & $<0.001$ \\
\hline Voice disturbance ${ }^{c}$ & $784.4,784.5$ & 23 & 0.1 & $44,973[57,858]$ & 0.140 \\
\hline
\end{tabular}

${ }^{\mathrm{a}}$ Sum of the charges for (1) medical claims with an MS diagnosis (ICD-9-CM = 340.xx in any diagnosis field or a DRG code for MS and cerebellar ataxia [DRG =058, 059, or 060]) plus (2) medical or pharmacy claims indicating a DMD (Table 1).

${ }^{b}$ ICD-9-CM coding except where otherwise specified.

'Identified by Prescott et al. using a combination of ICD-9-CM codes and ETG coding [10].

didentified by Prescott et al. using only ETG coding [10].

DMD = disease-modifying drug; DRG = Diagnosis-Related Group; ETG = Episode Treatment Group; ICD-9-CM = International Classification of Diseases, Ninth Revision, Clinical Modification; MS = multiple sclerosis; $S D=$ standard deviation.

with 47.1 years and $77 \%$ female in the Prescott et al. sample. Results of the present study indicated that total inflation-adjusted MS health care charges increased by 60\% from 2006 to 2011 and pointed to a number of important cost drivers.

Foremost, like Prescott et al., we found that common disease sequelae are associated with substantially higher charges for MS-related health care [10]. In both studies, optic neuritis was associated with a charge of more than $200 \%$ above average but was rare, affecting $0.4 \%$ of the Prescott et al. sample and $0.2 \%$ of the present study sample. Abnormality of gait was experienced by $7.4 \%-7.5 \%$ of the patients in both samples; it was associated with charges of $62 \%$ and $82 \%$ above average in the Prescott et al. study and the present study, respectively.

Malaise and fatigue, depression, and paresthesia were the highest-prevalence disease sequelae in both studies [10]. However, in the present study compared with the study by Prescott et al., these conditions were lower in prevalence ( $8 \%-14 \%$ vs. $17 \%-22 \%$, respectively) and associated with greater charge increases (27\%-62\% above average in the present study vs. no significant difference for paresthesia and charge increases of $8 \%-13 \%$ for depression and malaise/fatigue in the study by Prescott et al.). These variations may be partly due to methodological differences. Specifically, the present study used diagnosis and DRG codes to identify disease sequelae and to calculate MS-related charges, whereas the study by Prescott et al. used the ETG methodology. However, it is possible that changes in MS treatment practices, including the promulgation of several guidelines since 2004, have resulted in changes in the reporting, prevalence, and/or cost of disease sequelae.

The present study found an inverted U-shaped distribution of charges by age, peaking at the ages of 36 to 55 years and dropping among patients aged 65 years or older. This result is similar to that obtained by Prescott et al., although as expected, charges were lower in 2004 than in 2011. Prescott et al. found mean 1-year MSrelated charges of $\$ 4,464$ for those younger than 18 years, $\$ 13,130-\$ 13,525$ for those aged 36 to 55 years, and $\$ 9,677$ for those aged 65 years or older.

Unlike Prescott et al., we did not find a decline in medical charges when we examined change over time, although we did find that medical charges increased at a lower rate of growth than did DMD charges in the sample overall, including both DMD users and patients not treated with DMDs. Nonetheless, among DMD monotherapy users in 2011, DMD charges were responsible for $75 \%$ of treatment costs, similar to the proportion reported by Prescott et al. (73\%) for patients treated with DMD monotherapy in 2004 [10].

The increase in DMD charges from 2006 to 2011 in the sample overall may be attributable to an increased number of available DMDs, as well as price inflation among existing DMDs [28]. A surprising finding of the present study is that the proportion of continuously enrolled patients with at least 1 DMD claim remained constant at about 53\%-54\% from 2006 to 2011. Also surprising is that the DMD use rate estimated in the present study is 
Table 4 DMD utilization and patient characteristics: patients with MS in 2011

\begin{tabular}{|c|c|c|c|c|c|c|}
\hline & IFN beta-1a IM & IFN beta-1b & Glatiramer acetate & IFN beta-1a SC & Natalizumab & Total \\
\hline All DMD users—n (\%) & $1,827(22.4)$ & $902(11.1)$ & $3,261(40.0)$ & $1,725(21.1)$ & $800(9.8)$ & 8,145 \\
\hline $\begin{array}{l}\text { DMD monotherapy } \\
\text { users_n (\%) }\end{array}$ & $1,718(22.0)$ & $842(10.8)$ & $3,029(38.8)$ & $1,544(19.8)$ & $672(8.6)$ & 7,805 \\
\hline
\end{tabular}

\section{Characteristics of DMD monotherapy users in 2011}

\begin{tabular}{|c|c|c|c|c|c|c|c|c|c|c|c|}
\hline & \multicolumn{2}{|c|}{ IFN beta-1a IM } & \multicolumn{2}{|c|}{ IFN beta-1b } & \multicolumn{2}{|c|}{ Glatiramer acetate } & \multicolumn{2}{|c|}{ IFN beta-1a SC } & \multicolumn{2}{|c|}{ Natalizumab } & $P$ value \\
\hline \multicolumn{12}{|l|}{ Demographics } \\
\hline Gender n $(\%)^{b, c}$ & & & & & & & & & & & 0.002 \\
\hline Female & \multicolumn{2}{|c|}{$1,313(76.4)$} & \multicolumn{2}{|c|}{$622(73.9)$} & \multicolumn{2}{|c|}{$2,354(77.7)$} & \multicolumn{2}{|c|}{$1,122(72.7)$} & \multicolumn{2}{|c|}{$501(74.6)$} & \\
\hline Male & \multicolumn{2}{|c|}{$404(23.5)$} & \multicolumn{2}{|c|}{$220(26.1)$} & \multicolumn{2}{|c|}{$675(22.3)$} & \multicolumn{2}{|c|}{$422(27.3)$} & \multicolumn{2}{|c|}{$171(25.4)$} & \\
\hline Mean $[S D]$ age $^{b}$ & \multicolumn{2}{|c|}{$49.6[10.1]$} & \multicolumn{2}{|c|}{$47.5[11.1]$} & \multicolumn{2}{|c|}{$47.3[11.0]$} & \multicolumn{2}{|c|}{$45.2[10.5]$} & \multicolumn{2}{|c|}{$45.6[10.1]$} & $<0.001$ \\
\hline Mean [SD] DMD claims ${ }^{\mathrm{b}, \mathrm{d}}$ & \multicolumn{2}{|c|}{$9.21[4.34]$} & \multicolumn{2}{|c|}{$9.09[3.91]$} & \multicolumn{2}{|c|}{$5.95[4.14]$} & \multicolumn{2}{|c|}{$9.03[4.10]$} & \multicolumn{2}{|c|}{$8.92[3.98]$} & $<0.001$ \\
\hline Mean [SD] days supply $y^{b, d}$ & \multicolumn{2}{|c|}{$274.6[93.4]$} & \multicolumn{2}{|c|}{$265.3[95.5]$} & \multicolumn{2}{|c|}{$186.3[122.3]$} & 260.9 & 5.2] & 241.3 & 07.8] & $<0.001$ \\
\hline $\begin{array}{l}\text { Mean [SD] days until } \\
\text { DMD start }{ }^{b, d}\end{array}$ & 45.80 & $.49]$ & 41.57 & 2.24] & 76.43 & 3.28] & 54.17 & $80]$ & 49.05 & 4.87] & $<0.001$ \\
\hline Disease sequelae ${ }^{\mathrm{b}}$ & & & & & & & & & & & \\
\hline Abnormality of gait & 104 & & 80 & & 247 & & 133 & & 107 & & $<0.001$ \\
\hline Ataxia & 20 & & 26 & & 68 & & 37 & & 29 & & $<0.001$ \\
\hline $\begin{array}{l}\text { Burning, numbness, } \\
\text { tingling sensations }\end{array}$ & 160 & & 80 & & 305 & & 174 & & 94( & & 0.008 \\
\hline Convulsions & $0(C$ & & 0( & & $0(C$ & & 0( & & 0 ( & & NA \\
\hline Depression & 125 & & 74 & & 279 & & 143 & & 90( & & $<0.001$ \\
\hline Fecal incontinence & $0(C$ & & 0( & & $0(C$ & & 0( & & 0( & & NA \\
\hline $\begin{array}{l}\text { Fibromyalgia/myalgia } \\
\text { and myositis }\end{array}$ & 26 & & 15 & & 84 & & 27 & & 24 & & 0.003 \\
\hline Malaise and fatigue & 209 & & 137 & & 493 & & 261 & & 187 & & $<0.001$ \\
\hline Optic neuritis & $2(C$ & & 2( & & $4(C$ & & 2( & & 2( & & 0.809 \\
\hline Spasms & 33( & & 23 & & 73 & & 39 & & 37 & & $<0.001$ \\
\hline Trigeminal neuralgia & 14( & & 5( & & 30 & & 15 & & 9( & & 0.621 \\
\hline Urinary incontinence & 31 & & 21 & & 61 & & 23 & & 29 & & $<0.001$ \\
\hline Voice disturbance & $4(C$ & & 0( & & $6(C$ & & 1( & & 2( & & 0.449 \\
\hline MS charge components ${ }^{b}$ & $\begin{array}{c}\text { Mean } \\
{[S D](\$)}\end{array}$ & $\begin{array}{l}\% \text { of } \\
\text { Total }\end{array}$ & $\begin{array}{c}\text { Mean } \\
{[S D](\$)}\end{array}$ & $\begin{array}{l}\% \text { of } \\
\text { Total }\end{array}$ & $\begin{array}{c}\text { Mean } \\
{[S D](\$)}\end{array}$ & $\begin{array}{l}\% \text { of } \\
\text { Total }\end{array}$ & $\begin{array}{c}\text { Mean } \\
{[S D](\$)}\end{array}$ & $\begin{array}{l}\% \text { of } \\
\text { Total }\end{array}$ & $\begin{array}{c}\text { Mean } \\
\text { [SD] (\$) }\end{array}$ & $\begin{array}{l}\% \text { of } \\
\text { Total }\end{array}$ & $P$ value \\
\hline Inpatient ${ }^{\mathrm{e}}$ & $\begin{array}{c}2,061 \\
{[12,706]}\end{array}$ & 4.5 & $\begin{array}{c}3,093 \\
{[15,185]}\end{array}$ & 6.4 & $\begin{array}{c}3,053 \\
{[18,590]}\end{array}$ & 7.9 & $\begin{array}{c}2,557 \\
{[14,226]}\end{array}$ & 5.6 & $\begin{array}{c}3,610 \\
{[17,308]}\end{array}$ & 4.4 & 0.155 \\
\hline Outpatient $^{\mathrm{e}}$ & $\begin{array}{c}6,485 \\
{[18,322]}\end{array}$ & 14.2 & $\begin{array}{c}7,931 \\
{[27,432]}\end{array}$ & 16.3 & $\begin{array}{c}7,736 \\
{[19,461]}\end{array}$ & 20.1 & $\begin{array}{c}7,540 \\
{[22,866]}\end{array}$ & 16.4 & $\begin{array}{c}23,702 \\
{[26,046]}\end{array}$ & 29.0 & $<0.001$ \\
\hline Emergency room ${ }^{e}$ & 15 [323] & 0.0 & 7 [97] & 0.0 & 27 [374] & 0.1 & 28 [364] & 0.1 & 60 [651] & 0.1 & 0.059 \\
\hline DMD & $\begin{array}{c}37,209 \\
{[13,042]}\end{array}$ & 81.3 & $\begin{array}{c}37,498 \\
{[14,007]}\end{array}$ & 77.3 & $\begin{array}{c}27,694 \\
{[18,055]}\end{array}$ & 71.9 & $\begin{array}{l}35,803 \\
{[14,766]}\end{array}$ & 78.0 & $\begin{array}{c}54,255 \\
{[34,102]}\end{array}$ & 66.5 & $<0.001$ \\
\hline Total & $\begin{array}{c}45,770 \\
{[25,674]}\end{array}$ & 100.0 & $\begin{array}{c}48,529 \\
{[33,932]}\end{array}$ & 100.0 & $\begin{array}{c}38,509 \\
{[32,570]}\end{array}$ & 100.0 & $\begin{array}{l}45,928 \\
{[30,434]}\end{array}$ & 100.0 & $\begin{array}{c}81,627 \\
{[42,528]}\end{array}$ & 100.0 & $<0.001$ \\
\hline
\end{tabular}

${ }^{a}$ Counts (\%) sum to more than the total DMD user cohort size (100\%) because patients could be treated with more than 1 DMD during the year. ${ }^{b}$ Calculated for patients using a single DMD during $2011(n=7,805)$.

'Table and chi-square test exclude 1 patient treated with IFN beta-1a with missing gender information.

dincludes both medical and pharmacy claims. Days until DMD start represents the number of days from January 1, 2011, until the date of the first DMD claim. For medical claims, days supply was estimated based on the expected dosing schedule for each DMD (count of injections $\times$ interval based on dosing schedule).

${ }^{\text {e}}$ Charges for medical claims with an MS diagnosis (ICD-9-CM $=340 . x x$ in any diagnosis field or a DRG code for MS).

$\mathrm{DMD}=$ disease-modifying drug; IFN = interferon; IM = intramuscular; $\mathrm{MS}=$ multiple sclerosis; $\mathrm{SC}=$ subcutaneous; $\mathrm{SD}=$ standard deviation. 
Table 5 Comparison of MS charges for 2006 and 2011

\begin{tabular}{lccc}
\hline Study year and cohort & \multicolumn{3}{c}{ Service component } \\
\cline { 2 - 4 } & Medical & DMD & Total \\
\hline $2006(n=15,399)$ & 7,966 & 5,989 & 13,955 \\
Charges $(\$)$ & 9,484 & 7,130 & 16,614 \\
Adjusted charges $(\$)^{\mathrm{a}}$ & $57.1 \%$ & $42.9 \%$ & \\
Percentage of total charges & & & \\
$2011(\mathrm{n}=15,902)$ & 12,567 & 13,953 & 26,520 \\
Charges (\$) & $47.4 \%$ & $52.6 \%$ & \\
Percentage of total charges & $32.5 \%$ & $95.7 \%$ & $59.6 \%$ \\
Percentage change from & & & \\
adjusted 2006 to 2011 & & & \\
\hline
\end{tabular}

${ }^{a}$ Adjusted for the medical component of the Consumer Price Index. $\mathrm{DMD}=$ disease-modifying drug; $\mathrm{MS}=$ multiple sclerosis.

less than the $58 \%$ reported by Prescott et al. for patients treated in 2004 [10]. It is possible that physicians have either maintained or slightly declined their rate of adoption of DMDs. It is also possible that the diagnosed population has changed over time to include a greater proportion of patients with forms of MS not FDAapproved for treatment with DMDs, such as nonrelapsing MS. ICD-9-CM coding does not distinguish between types of MS and therefore cannot be used to provide an answer to that question.

The addition of natalizumab to the treatment armamentarium in 2006 likely contributed to higher charges for both pharmacy and medical services in the present study. In the analysis of the DMD monotherapy cohort, patients treated with natalizumab incurred the highest MS charges, especially in the outpatient service category. This difference may be partly due to higher rates of disease sequelae associated with greater disease severity, because the Risk Evaluation and Mitigation Strategy (REMS) program under which natalizumab is made available calls for its use only as a second-line drug [24,29,30]. Greater resource utilization for patients treated with natalizumab may also result from REMS program requirements for a schedule of outpatient monitoring and magnetic resonance imaging scan prior to the start of treatment $[24,29,30]$.

\section{Limitations}

The foremost limitations of the present study arise from methodological uncertainty in replicating a study based on a proprietary methodology. Patients in the analysis by Prescott et al. were required to have both a diagnosis of MS and an ETG indicating central nervous system inflammation, and ETG codes were used to capture MSrelated charges [10]. Additionally, the database used by Prescott et al. included publicly funded health plans (i.e., Medicare, Medicaid), whereas the current study database was limited to commercially insured patients. Despite these limitations, the age distributions of the samples were similar, and both studies identified similar lists of disease sequelae as cost drivers.

Second, the present study, like that of Prescott et al., was limited to direct health care charges, although indirect costs due to MS are substantial and increase at higher disease severity levels [9]. Additionally, the study's results are based on U.S. patients and may not generalize to other countries; a systematic review by Naci et al. (2010) found that "cost drivers varied across geographies likely due to the significant differences in the availability of services and resource use patterns across countries" [9]. Finally, because all study patients were continuously enrolled, results cannot be used to draw conclusions about mortality related to MS.

Third, the present study's finding of lower claims counts and days supply for glatiramer acetate than for the other DMDs among monotherapy users was related to a later start date in calendar year 2011-averages of 76 days (March 18) versus 42 to 54 days (February 12 to February 24), respectively. This finding, which is not consistent with the results of Prescott et al., may be due to plan formulary or benefit design requirements that are not visible within the study database. However, there is no reason to believe that it had a substantial effect on key study results. For example, excluding patients treated with glatiramer acetate, the proportion of total MS cost attributable to DMDs is $76 \%$, similar to the $75 \%$ for DMD monotherapy-treated patients overall.

Fourth, although DMD monotherapy users in 2006 might have provided a better point of comparison than the sample of Prescott et al. for the analysis of change in DMD proportional cost over time, use of this subsample was not possible for the 2006 cohort because of difficulties in obtaining detailed cost data. The analysis of 2006 was limited to a secondary objective of the present study.

Fifth, because of its 12-month follow-up time, the present study did not meet the need for longitudinal cohort data for patients with MS [26]. To provide information about the potential cost implications of natural disease history changes due to DMD use, cohort studies with a longer follow-up time are an important area for future research.

\section{Conclusion}

Over a 5-year period from 2006 to 2011, total inflationadjusted, MS-related charges increased by 60\%. MSrelated costs among patients treated with different DMDs ranged from 1-year means of $\$ 38,509$ to $\$ 81,627$. For DMD monotherapy users, $75 \%$ of total MS-related health care cost in 2011 was for DMDs, similar to the percentage previously reported for patients treated in 2004. Sequalae of MS contributed significantly to the total cost of care. 


\section{Competing interests}

This work was sponsored by Teva Pharmaceuticals, which manufactures glatiramer acetate. Carroll is a former employee and former stockholder of Teva. Fairman and Lage are consultants to Teva and were compensated by Teva for their work on this study and on other studies. Teva funded the article processing charge for the manuscript. The authors have no additional financial competing interests and no nonfinancial competing interests.

\section{Authors' contributions}

CC had primary responsibility for study concept and design. ML performed data analyses. KF drafted and edited the manuscript. All authors made substantial contributions to concept/design and data interpretation, participated in critical review and revision of the manuscript, and take public responsibility for its content. All authors read and approved the final manuscript.

\section{Author details}

${ }^{1}$ Managed Markets, Xcenda; formerly Health Economics and Outcomes Research, Teva Pharmaceuticals, Kansas City, MO, USA. ${ }^{2}$ Kathleen Fairman LTD, 11208 North 23rd Place, Phoenix, AZ, USA. ${ }^{3}$ HealthMetrics Outcomes Research, LLC, Bonita Springs, FL, USA.

Received: 10 August 2013 Accepted: 16 June 2014

Published: 2 July 2014

\section{References}

1. Noseworthy JH, Lucchinetti C, Rodriguez M, Weinshenker BG: Multiple sclerosis. N Engl J Med 2000, 343(13):938-952.

2. Hirtz D, Thurman DJ, Gwinn-Hardy K, Mohamed M, Chaudhuri AR, Zalutsky $\mathrm{R}$ : How common are the "common" neurologic disorders? Neurology 2007, 68(5):326-337.

3. Whetten-Goldstein K, Sloan FA, Goldstein LB, Kulas ED: A comprehensive assessment of the cost of multiple sclerosis in the United States. Mult Scler 1998, 4(5):419-425.

4. Miller RM, Happe LE, Meyer KL, Spear RJ: Approaches to the management of agents used for the treatment of multiple sclerosis: consensus statements from a panel of U.S. managed care pharmacists and physicians. J Manag Care Pharm 2012, 18(1):54-62

5. Cohen JA, Rudick RA: Aspects of Multiple Sclerosis That Relate to Trial Design and Clinical Management. In Multiple Sclerosis Therapeutics. 3rd edition. Edited by Cohen JA, Rudick RA. Boca Raton, FL: Taylor \& Francis; 2007:3-22.

6. Goodin DS, Frohman EM, Garmany GP Jr, Halper J, Likosky WH, Lublin FD, Silberburg DH, Stuart WH, van den Noort S, Therapeutics and Technology Assessment Subcommittee of the American Academy of Neurology and the MS Council for Clinical Practice Guidelines: Disease modifying therapies in multiple sclerosis: report of the Therapeutics and Technology Assessment Subcommittee of the American Academy of Neurology and the MS Council for Clinical Practice Guidelines. Neurology 2002, 58(2):169-178

7. National Multiple Sclerosis Society: Expert Opinion Paper: National Clinical Advisory Board of the National Multiple Sclerosis Society. Disease Management Consensus Statement. 2008, http://www.nationalmssociety.org/ NationalMSSociety/media/MSNationalFiles/Brochures/ExpOp_Consensus.pdf.

8. Goldberg LD, Edwards NC, Fincher C, Doan QV, AL-Sabbagh A, Meletiche DM: Comparing the cost-effectiveness of disease-modifying drugs for the first-line treatment of relapsing-remitting multiple sclerosis. J Manag Care Pharm 2009, 15(7):543-555.

9. Naci H, Fleurence R, Birt J, Duhig A: Economic burden of multiple sclerosis: a systematic review of the literature. Pharmacoeconomics 2010, 28(5):363-379.

10. Prescott JD, Factor S, Pill M, Levi GW: Descriptive analysis of the direct medical costs of multiple sclerosis in 2004 using administrative claims in a large nationwide database. J Manag Care Pharm 2007, 13(1):44-52.

11. Pope GC, Urago CJ, Kulas ED, Kronick R, Gilmer T: Prevalence, expenditures, utilization, and payment for persons with MS in insured populations. Neurology 2002, 58(1):37-43.

12. Bell CF: The pursuit of transparency and quality improvement in cost-effectiveness analysis: a case study in disease-modifying drugs for the treatment of multiple sclerosis. J Manag Care Pharm 2011, 17(6):463-468.
13. Watkins JB, Sullivan SD: The payer's dilemma: recognizing the uncertainty of clinical and economic evidence at product launch. J Manag Care Pharm 2009, 15(2):167-169.

14. Aforismo JF, Pill MW, Prescott JD: Initiating drug therapy in multiple sclerosis. American Journal of Pharmacy Benefits 2010, 2(1):59-65.

15. Asche CV, Singer ME, Jhaveri M, Chung H, Miller A: All-cause health care utilization and costs associated with newly diagnosed multiple sclerosis in the United States. J Manag Care Pharm 2010, 16(9):703-712.

16. Tan H, Cai Q, Agarwal S, Stephenson JJ, Kamat S: Impact of adherence to disease-modifying therapies on clinical and economic outcomes among patients with multiple sclerosis. Adv Ther 2011, 28(1):51-61.

17. Castelli-Haley J, Oleen-Burkey MA, Lage MJ, Johnson K: Glatiramer acetate and interferon beta-1a for intramuscular administration: a study of outcomes among multiple sclerosis intent-to-treat and persistent-use cohorts. J Med Econ 2010, 13(3):464-471.

18. Birnbaum HG, Ivanova Jl, Samuels S, Davis M, Cremieux PY, Phillips AL, Meletiche D: Economic impact of multiple sclerosis disease-modifying drugs in an employed population: direct and indirect costs. Curr Med Res Opin 2009, 25(4):869-877.

19. Curkendall SM, Wang C, Johnson BH, Cao Z, Preblick R, Torres AM, Knappertz V, Gondek K: Potential health care cost savings associated with early treatment of multiple sclerosis using disease-modifying therapy. Clin Ther 2011, 33(7):914-925

20. Ivanova JI, Bergman RE, Birnbaum HG, Phillips AL, Stewart M, Meletiche DM: Impact of medication adherence to disease-modifying drugs on severe relapse, and direct and indirect costs among employees with multiple sclerosis in the US. J Med Econ 2012, 15(3):601-609.

21. Trisolini MG: Comparison of Multiple Sclerosis Guidelines Underscores Need for Collaboration. U.S. Department of Health and Human Services, National Guideline Clearinghouse; 2008. http://www.guideline.gov/expert/expertcommentary.aspx?id=16443.

22. U.S. Department of Health and Human Services, National Guideline Clearinghouse: Guidelines by Topic: Multiple Sclerosis. [http://www. guideline.gov/search/search.aspx?term=multiple+sclerosis]

23. U.S. Food and Drug Administration: Important new Information - on Natalizumab (Marketed as Tysabri). 2006, http://www.accessdata.fda.gov/ scripts/cdrh/cfdocs/psn/transcript.cfm?show=52.

24. U.S. Food and Drug Administration: FDA News Release. FDA Approves Resumed Marketing of Tysabri Under a Special Distribution Program. 2006, (updated June 6, 2006) http://www.fda.gov/NewsEvents/Newsroom/ PressAnnouncements/2006/ucm108662.htm.

25. U.S. Food and Drug Administration: Center Watch. Extavia (interferon beta 1-b). [http://www.centerwatch.com/drug-information/fda-approvals/drugdetails.aspx?Drug|D=1045]

26. Hawton A, Shearer J, Goodwin E, Green C: Squinting through layers of fog: assessing the cost effectiveness of treatments for multiple sclerosis. Appl Health Econ Health Policy 2013, 11(4):331-341.

27. Weinstein MC, O'Brien B, Hornberger J, Jackson J, Johannesson M, McCabe C, Luce BR, ISPOR Task Force of Good Research Practices-Modeling Studies: Principles of good practice for decision analytic modeling in health-care evaluation: report of the ISPOR task force on good research practices-modeling studies. Value Health 2003, 6(1):9-17.

28. Schafer JA, Gunderson BW, Gleason PP: Price increases and new drugs drive increased expenditures for multiple sclerosis. J Manag Care Pharm 2010, 16(9):713-717.

29. U.S. Food and Drug Administration: FDA Drug Safety Communication: New Risk Factor for Progressive Multifocal Leukoencephalopathy (PML) Associated With Tysabri (Natalizumab). 2012, http://www.fda.gov/Drugs/ DrugSafety/ucm288186.htm.

30. U.S. Food and Drug Administration: Risk Evaluation and Mitigation Strategy (REMS). Tysabri Outreach. Unified Commitment to Health (TOUCH ${ }^{\circledR}$ ) Prescribing Program (MS \& CD). http://www.fda.gov/downloads/Drugs/ DrugSafety/PostmarketDrugSafetylnformationforPatientsandProviders/ UCM288126.pdf

doi:10.1186/1472-6963-14-286

Cite this article as: Carroll et al:: Updated cost-of-care estimates for commercially insured patients with multiple sclerosis: retrospective observational analysis of medical and pharmacy claims data. BMC Health Services Research 2014 14:286. 